\title{
Germinação de Conídios de Sphaerotheca pannosa Obtidos de Eucalipto
}

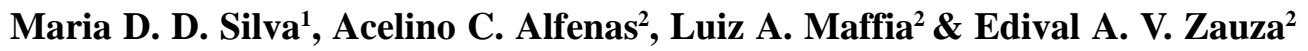 \\ ${ }^{1}$ Departamento de Engenharia Florestal, ${ }^{2}$ Departamento de Fitopatologia, Universidade Federal de Viçosa, CEP 36571-000, \\ Viçosa, MG, e-mail: aalfenas@ufv.br
}

(Aceito para publicação em 08/08/2003)

Autor para correspondência: Acelino Couto Alfenas.

SILVA, M.D.D., ALFENAS, A.C., MAFFIA, L.A. \& ZAUZA, E.A.V. Germinação de conídios de Sphaerotheca pannosa obtidos de eucalipto. Fitopatologia Brasileira 28:674-681. 2003.

\section{RESUMO}

Estudou-se a germinação de conídios de Sphaerotheca pannosa em diferentes meios-suporte sob diferentes regimes de umidade relativa, fotoperíodo e temperatura. Às $24 \mathrm{~h}$ da incubação, avaliou-se a germinação em ágar-água, lâmina de vidro e folha destacada, sob condições de câmara úmida. Não se constatou germinação de conídios em lâmina de vidro escavada, ou placas de Petri, na presença de água livre. A germinação do patógeno foi favorecida por umidade relativa próxima a $100 \%$, fotoperíodo de $12 \mathrm{~h}$, com exposição inicial à luz e temperaturas de 20 a $25^{\circ} \mathrm{C}$.

Palavras-chave adicionais: Eucalyptus sp., oídio, epidemiologia.

\section{ABSTRACT}

Conidial germination of Sphaerotheca pannosa collected from eucalyptus

The conidial germination of Sphaerotheca pannosa was studied in different supporting media, under different levels of relative humidity (RH), photoperiod and temperature. At $24 \mathrm{~h}$ of incubation, conidial germination was assessed on water agar, glass slides and leaves of eucalyptus (Eucalyptus citriodora) kept in a moisture chamber. Conidial germination did not occur on slides or Petri dishes in the presence of free water. Optimum conidial germination was found at 20 and $25^{\circ} \mathrm{C}, 100 \% \mathrm{RH}$ and with $12 \mathrm{~h}$ of initial light exposure.
O oídio do eucalipto (Eucalyptus citriodora Hook), causado pelo fungo Sphaerotheca pannosa Wallr. Ex. Fries Lév., tem sido freqüentemente encontrado em mudas de eucalipto na fase de viveiro em várias regiões de Minas Gerais e, em outras espécies do mesmo gênero, a doença tem sido comumente observada em casa de vegetação. Incide em folhas e brotos jovens, causando enrugamentos, deformações do limbo e superbrotamento das plantas (Ferreira, 1997), podendo acarretar a morte de até 50\% das mudas (Mucci et al., 1980). No Brasil, apenas a fase anamórfica do agente etiológico tem sido encontrada e identificada como Oidium eucalypti Rostrup. (Ferreira, 1989). O patógeno utiliza nutrientes do hospedeiro, reduz sua fotossíntese, aumenta sua respiração e transpiração, resultando na redução do desenvolvimento e produtividade da planta (Agrios, 1997).

A disseminação do patógeno e a severidade da doença são altamente influenciadas pela radiação, temperatura, precipitação, evapotranspiração, condensação de água, umidade relativa e pelo vento (Aust \& Hoyningen-Huene, 1986). A germinação de conídios é favorecida por condições atmosféricas relativamente secas, temperaturas moderadas, luz reduzida (Yarwood, 1957) e umidade relativa próxima a 100\% (Weinhold, 1961; Jhooty \& McKeen, 1965; Mishina \& Talieva,
1988). Assim, o conhecimento dos fatores climáticos que afetam o patógeno é imprescindível para embasar medidas de controle da doença.

Neste trabalho, procurou-se avaliar a germinação in vitro de conídios de $S$. pannosa em diferentes meios-suporte e sob diferentes regimes de umidade relativa, fotoperíodo e temperatura.

\section{Germinação de conídios de Sphaerotheca pannosa sob diferentes meios-suporte}

Avaliou-se a germinação de conídios do patógeno sobre folhas destacadas de eucalipto, lâminas de vidro secas, meio de ágar-água e em água em lâminas escavadas. Após deposição de esporos sobre cada meio-suporte testado, efetuou-se a incubação sob condições de câmara úmida convencional, a $20^{\circ} \mathrm{C}\left( \pm 1^{\circ} \mathrm{C}\right.$ ), fotoperíodo de $12 \mathrm{~h}$ (luz branca) com exposição inicial à luz, durante $24 \mathrm{~h}$. A germinação foi interrompida pela adição de azul de Amann (lactofenol/azul de algodão) e, a seguir, cobriu-se a amostra com uma lamínula para facilitar a avaliação dos resultados. Determinou-se a germinação de 100 conídios por repetição, visualizados aleatoriamente, no campo microscópico (400 X). Considerou-se germinados os conídios com tubo germinativo maior, ou igual, a sua menor dimensão. 
Para cada tratamento, empregaram-se quatro repetições, perfazendo um total de 400 esporos amostrados.

Para o teste de germinação em folhas destacadas de eucalipto, folhas de Eucalyptus pellita F. Muell foram coletadas e, em seguida, desinfestadas em solução aquosa de hipoclorito de sódio a 100 ppm de cloro ativo durante $1 \mathrm{~min}$; depois, foram lavadas em água destilada esterilizada e, a seguir, secas em papel toalha. Para inoculação, tocou-se levemente a folha destacada sadia em outra folha infetada de E. pellita contendo esporulação do fungo. Para facilitar a avaliação dos resultados, os conídios foram transferidos para lâminas de vidro para microscopia, passando uma das superfícies da lâmina sobre a área foliar inoculada.

Em relação ao teste de germinação em lâmina de vidro, utilizaram-se quatro lâminas, devidamente limpas, esterilizadas e secas. Para a deposição de inóculo, uma das superfícies de cada lâmina foi passada levemente sobre as folhas de eucalipto contendo esporulação do patógeno.

Quanto à germinação em ágar-água e em água deionizada procedeu-se da seguinte forma: em quatro placas de Petri, depositaram-se $15 \mathrm{ml}$ de ágar-água fundente a $1 \%$ e, em quatro lâminas escavadas, $200 \mu \mathrm{l}$ de água deionizada esterilizada. Mediante o uso de um pincel de cerdas macias, transferiram-se conídios de folhas infetadas para as placas e para as lâminas escavadas.

\section{Germinação de conídios sob diferentes níveis de umidade relativa, fotoperíodo e temperatura}

Umidade relativa. Folhas de E. pellita com infecção natural de $S$. pannosa, em casa de vegetação, foram lavadas com um leve jato de água, corrente, destilada, a fim de remover os esporos. Após quatro a cinco dias de incubação em câmara de crescimento a $20{ }^{\circ} \mathrm{C}\left( \pm 1{ }^{\circ} \mathrm{C}\right), 80 \%$ de umidade relativa e fotoperíodo de $12 \mathrm{~h}$, os conídios produzidos foram removidos e depositados em lâminas de vidro secas, por meio de contato com folhas infetadas. Utilizando a metodologia citada por Dhingra \& Sinclair (1985), testou-se o efeito da umidade relativa sobre a germinação de conídios. Para isto, empregaram-se oito dessecadores, contendo $200 \mathrm{ml}$ de solução aquosa saturada de $\mathrm{K}_{2} \mathrm{CO}_{3}, \mathrm{Mg}\left(\mathrm{NO}_{3}\right)_{2} \cdot 6 \mathrm{H}_{2} \mathrm{O}, \mathrm{COCl}_{2} \cdot 6 \mathrm{H}_{2} \mathrm{O}, \mathrm{NH}_{4} \mathrm{C} 1, \mathrm{MgSO}_{4} \cdot 7 \mathrm{H}_{2} \mathrm{O}$, $\mathrm{Na}_{2} \mathrm{HPO}_{4} \cdot 7 \mathrm{H}_{2} \mathrm{O}, \mathrm{CaSO}_{4}$ e água destilada, de modo a se obter, respectivamente, 44, 55, 67, 80, 90, 95, 98 e $100 \%$ de UR. Antes de transferir as lâminas com os conídios do fungo para os dessecadores, aguardou-se $24 \mathrm{~h}$ para que a umidade no interior dos dessecadores estabilizasse. Obtido o equilíbrio dos níveis de umidade relativa, as lâminas contendo conídios do fungo foram colocadas nos dessecadores, e estes mantidos em câmara de crescimento a $20^{\circ} \mathrm{C}\left( \pm 10^{\circ} \mathrm{C}\right)$ e fotoperíodo de $12 \mathrm{~h}(3.000$ lux, lâmpadas fluorescentes luz do dia), com exposição inicial à luz. Utilizou-se o delineamento inteiramente casualizado com quatro repetições por tratamento, onde cada lâmina constituiu uma repetição. Avaliou-se a germinação 24 h após a incubação. Este ensaio foi repetido por mais duas vezes, para confirmação dos resultados.

Fotoperíodo. Avaliou-se a germinação de conídios de
S. pannosa, obtidos de colônias esporulantes com cinco dias de idade, sobre lâminas de vidro, mantidas em condições de câmara úmida (100\% UR), temperatura de $20^{\circ} \mathrm{C}\left( \pm 1^{\circ} \mathrm{C}\right)$ e luminosidade de, aproximadamente, 3.000 lux (lâmpadas fluorescentes luz do dia). Testaram-se oito regimes de fotoperíodo: $24 \mathrm{~h}$ de luz, $18 \mathrm{~h}$ de luz $+6 \mathrm{~h}$ de escuro, $12 \mathrm{~h}$ de luz $+12 \mathrm{~h}$ de escuro, $6 \mathrm{~h}$ de luz $+18 \mathrm{~h}$ de escuro, $24 \mathrm{~h}$ de escuro, 18 $\mathrm{h}$ de escuro $+6 \mathrm{~h}$ de luz, $12 \mathrm{~h}$ de escuro $+12 \mathrm{~h}$ de luz, $6 \mathrm{~h}$ de escuro +18 h de luz. Obteve-se a condição de escuro contínuo, cobrindo-se a câmara úmida com plástico preto. Após 24 h de incubação, interrompeu-se a germinação e contou-se o número de conídios germinados, conforme previamente descrito. $\mathrm{O}$ ensaio foi conduzido em delineamento inteiramente casualizado, com quatro repetições, constituídas pelas lâminas. $\mathrm{O}$ ensaio foi repetido por mais duas vezes.

Temperatura. Estudou-se a germinação de conídios de $S$. pannosa provenientes de colônias esporulantes com cinco dias de idade, a $10,15,20,25$, e $30^{\circ} \mathrm{C}$. Os conídios do patógeno foram depositados sobre lâminas de vidro esterilizadas e secas, mantidas em condição de câmara úmida (100\% UR), luminosidade de, aproximadamente, 3.000 lux (lâmpadas fluorescentes luz do dia) e fotoperíodo de $12 \mathrm{~h}$, com exposição inicial à luz, durante 24 h. A germinação foi interrompida conforme previamente descrito, e avaliada em 100 conídios por lâmina. Utilizou-se o delineamento inteiramente casualizado com quatro repetições, constituídas pelas lâminas. Para confirmação dos resultados, este ensaio foi repetido por mais duas vezes.

A germinação de conídios de $S$. pannosa, obtidos de eucalipto, não diferiu, significativamente, quando mantidos sobre folhas de eucalipto destacadas, lâminas de vidro ou ágarágua. Os conídios não germinaram em água deionizada (Tabela 1). Ainda que relativamente baixa, a germinação de conídios encontrada neste trabalho foi superior a obtida por Mucii et al. (1980) para o mesmo patógeno. Esses autores obtiveram apenas 15,08\% de germinação em água livre e 2,48\% em BDA. A germinação de conídios de $S$. pannosa obtida por Weinhold (1961) foi de 16,7 sobre folhas de pessegueiro [Prunus persicae (L.) Batsch] e 2,6\%, em lâminas de vidro.

Maior percentual de germinação foi obtido a $98 \%$ de umidade relativa e, entre 80 e $90 \%$, a germinação foi muito baixa, provavelmente devido à desidratação dos conídios. Em níveis de umidade relativa abaixo de $80 \%$ a germinação foi praticamente nula (Figura 1). Estes resultados confirmam, em parte, aqueles obtidos por Mucci et al. (1980) em que a germinação de conídios de Oidium eucalypti Rostrup foi máxima a $100 \%$ de umidade relativa. Resultados similares foram encontrados por Weinhold (1961), para conídios de S. pannosa, obtidos de pessegueiro. Maior índice de germinação de conídios e infecção máxima de Sphaerotheca macularis (Wallr.) Fr. foram conseguidos por Jhooty \& McKeen (1965), quando submeteram o patógeno e seu hospedeiro a $100 \%$ de umidade relativa.

Na presença de água livre, observaram-se conídios de S. pannosa com a membrana citoplasmática rompida, prova- 
TABELA 1 - Germinação de conídios de Sphaerotheca pannosa, obtidos do eucalipto (Eucalyptus spp.), em diferentes meios-suporte, a $20^{\circ} \mathrm{C}, 100 \%$ de umidade relativa e fotoperíodo de $12 \mathrm{~h}$, durante $24 \mathrm{~h}$

\begin{tabular}{lc}
\hline \hline Meio-suporte & Germinação (\%) \\
\hline Lâmina de vidro & $42,6 \mathrm{~A}^{\mathbf{1}}$ \\
Folha de eucalipto destacada & $35,7 \mathrm{~A}$ \\
Ágar-Água & $33,2 \mathrm{~A}$ \\
Água deionizada & $0,0 \mathrm{~B}$ \\
\hline
\end{tabular}

1 - Média de 400 esporos

2 - Médias seguidas da mesma letra não diferem estatisticamente, pelo teste de Tukey $(\mathrm{P}=0,01)$.

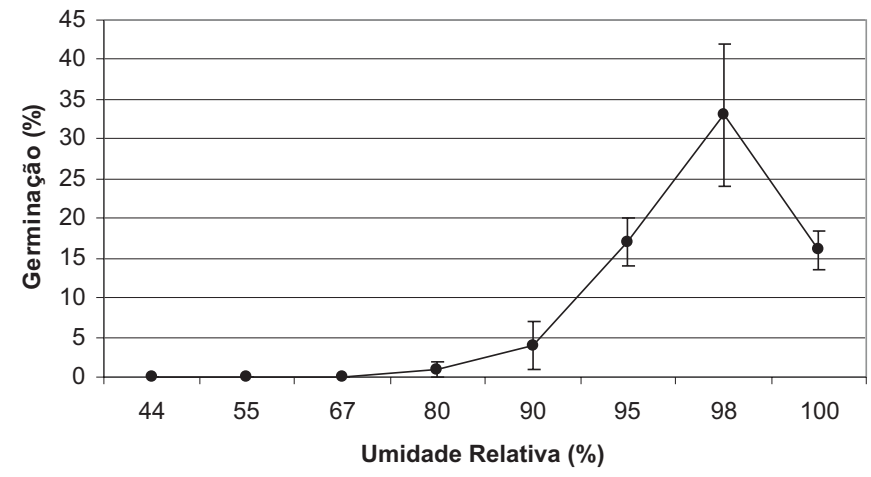

FIG. 1 - Germinação de conídios de Sphaerotheca pannosa, obtidas do eucalipto (Eucalyptus spp.), em lâminas de vidro, a $20{ }^{\circ} \mathrm{C}$ e fotoperíodo de $12 \mathrm{~h}$, durante $24 \mathrm{~h}$, sob diferentes níveis de umidade relativa. As barras indicam o desvio-padrão em relação às médias.

velmente em conseqüência da pressão de turgescência, fato que explica a inibição de sua germinação. Ademais, conídios de Oidium spp. germinam, satisfatoriamente, em ambiente com elevada umidade relativa, mas são inibidos por água livre na superfície do hospedeiro (Yarwood, 1957; Aust \& HoyningenHuene, 1986). Assim, a chuva é o fator climático que mais influencia negativamente as epidemias de oídios (Aust \& Hoyningen-Huene, 1986). Na prática, isto indica que o controle da doença pode ser favorecido, mediante irrigação por aspersão nos viveiros, de modo a manter um filme de água na superfície do hospedeiro.

A luz influenciou a germinação de conídios (Figura 2), mas seus efeitos não foram tão drásticos quanto os da temperatura (Figura 3) e da umidade relativa (Figura 1). O fotoperíodo de $12 \mathrm{~h}$ favoreceu a germinação de conídios de $S$. pannosa. Yarwood (1936) verificou que a severidade de oídio aumenta, dentro de certos limites, com o incremento do período de exposição à luz e que o comprimento médio das células das hifas de Erysiphe polygoni DC. foi crescente, quando plantas inoculadas foram submetidas aos períodos de luminosidade de $0,4,8$ até 12 h e decrescente, de 12 a 24 h. Os tubos germinativos e os conidióforos da maioria dos Oidium spp. têm fototropismo positivo (Yarwood 1936; Schinathost 1965). Ademais, seu desenvolvimento é também favorecido por altos

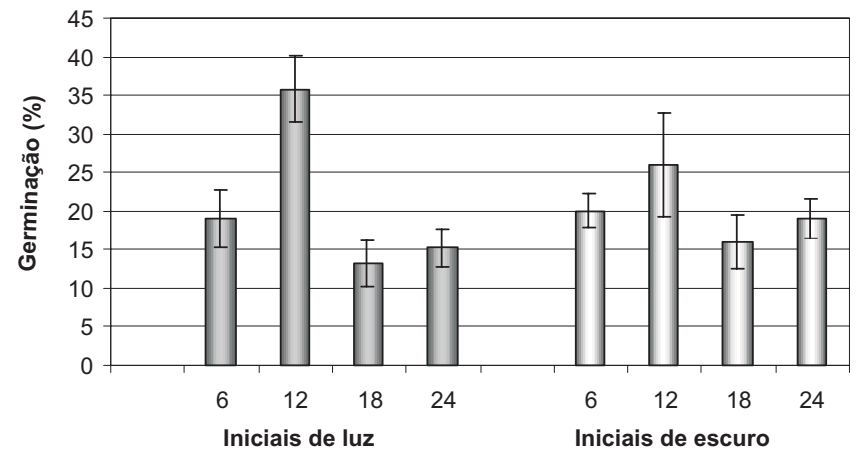

FIG. 2 -Germinação de conídios de Sphaerotheca pannosa obtidos do eucalipto (Eucalyptus spp.), em lâminas de vidro, a $20^{\circ} \mathrm{C}$ e $100 \%$ de umidade relativa, durante $24 \mathrm{~h}$, em diferentes regimes de fotoperíodos. As barras menores indicam o desvio-padrão em relação às médias.

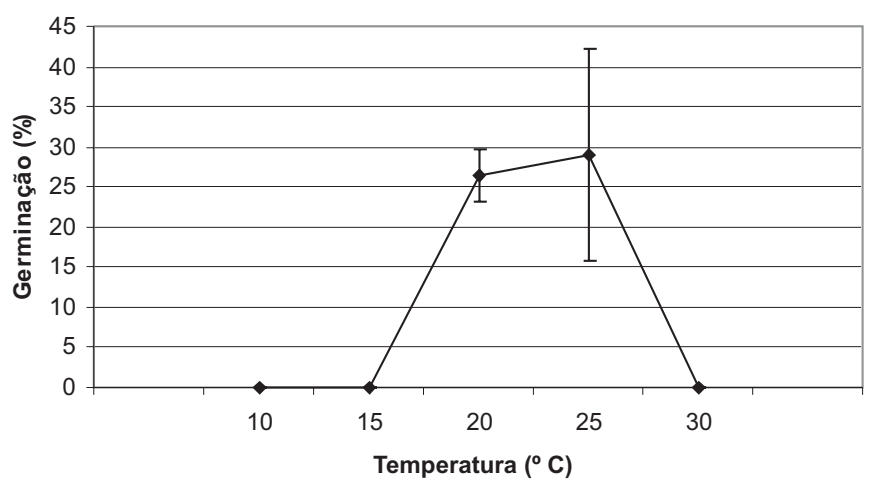

FIG. 3 - Germinação de conídios de Sphaerotheca pannosa obtidos do eucalipto (Eucalyptus spp.), em lâminas de vidro, a 100\% de umidade relativa e fotoperíodo de $12 \mathrm{~h}$, durante $24 \mathrm{~h}$, em diferentes níveis de temperatura. As barras indicam o desvio-padrão em relação às médias.

índices de carboidrato do hospedeiro. Deste modo, o efeito da luz sobre o hospedeiro pode afetar o patógeno, pois sob luz reduzida, a fotossíntese é também diminuída. Neste caso, o fotoperíodo de $12 \mathrm{~h}$, ideal para o crescimento do eucalipto pode favorecer o patógeno.

A temperatura exerceu influência marcante sobre a germinação de $S$. pannosa no eucalipto (Figura 3). Maiores percentuais de germinação foram obtidos na faixa de 20 a 25 ${ }^{\circ} \mathrm{C}$, chegando a $0 \%$, em $15{ }^{\circ} \mathrm{C}$ e $30{ }^{\circ} \mathrm{C}$. Estes resultados são semelhantes aos obtidos por Weinhold (1961) para conídios de $S$. pannosa, em que a temperatura ótima oscilou entre 21 e $27^{\circ} \mathrm{C}$. Análogamente, a germinação máxima de conídios de $O$. eucalypti foi a $25^{\circ} \mathrm{C}$ (Mucci et al., 1980). Para S. macularis e Oidium begoniae Puttemans a temperatura ótima de germinação foi de $20^{\circ} \mathrm{C}$ e $25^{\circ} \mathrm{C}$, respectivamente (Jhooty \& McKeen, 1965 ; Quinn \& Powel, 1982).

Para $S$. pannosa, como para a maioria das espécies de Oidium, temperaturas entre 20 e $25^{\circ} \mathrm{C}$, umidade relativa próxima a $100 \%$ e fotoperíodo de $12 \mathrm{~h}$, com exposição inicial à luz, favorecem a germinação de conídios. 
Germinação de conídios de Sphaerotheca pannosa obtidos de eucalipto

\section{REFERÊNCIAS BIBLIOGRÁFICAS}

AGRIOS, G.N. Plant patholo gy. 4. ed. New York, Academic Press, 1997.

AUST, H.J. \& HOYNINGEN-HUENE, J.V. Microclimate in relation to epidemics of pawdery mildew. Annual Review of Phytopathology 24:491-510. 1986.

DHINGRA, O.D. \& SINCLAIR, J.B. Basic plant pathology methods. Boca Raton, CRC Press, 1985.

FERREIRA, F.A. Patologia florestal: principais doenças florestais no Brasil. Viçosa, MG, SIF, 1989.

FERREIRA, F.A.A cultura do eucalipto II. Enfermidades do eucalipto no Brasil. Doenças em viveiros de eucalipto. Informe Agropecuário 18:5-19. 1997.

JHOOTY, J.S. \& McKEEN, W.E. Studies on powdery mildew of strawberry caused by Sahaerotheca macularis. Phytopathology 55:281285. 1965.

MISHINA, G. N. \& TALIEVA, M.N. Importance of air humidity in the process of conidial germination of powdery mildew of Phlox. Review of Plant Pathology 67:258. 1988.

MUCCI, E.S.F., PITTA, G.P.S. \& YOKOMIZO, N.K.S. O oídio em mudas de eucalipto. São Paulo, Instituto Florestal, Instituto Biológico, 1980. (mimeografado).

QUINN, J.A. \& POWEL, JR. C.C. Effects of temperature, light and relative humidity on powdery mildew of begonia. Phytopatology 5:480484. 1982.

SCHINATHORST, W.C. Environmental relationships in the powdery mildews. Annual Review of Phytopathology 3:343-346. 1965.

YARWOOD, C.E. The tolerante af Erysiphe polygoni and certain other powdery mildews to low humidity. Phytopathology 26:845-859. 1936. YARWOOD, C.E. Powdery mildews. The Botanical Review 23:235301. 1957.

WEINHOLD, A.R. Temperature and moisture requirements for germination of conidia of Sphaerotheca pannosa from peach. Phytopathology 51:699-703. 1961. 